\title{
Pulmonary capillary hemangiomatosis: an uncommon cause of pulmonary hypertension
}

\author{
Hemangiomatose capilar pulmonar: uma causa \\ incomum de hipertensão pulmonar
}

\author{
lgor Murad Faria, Leonardo Hoehl Carneiro, Teófilo Augusto Araújo Tiradentes, \\ Gláucia Zanetti, Edson Marchiori
}

\section{To the Editor:}

We read with interest the recent publications in the Brazilian Journal of Pulmonology highlighting the prevalence of pulmonary hypertension $(\mathrm{PH})$ in Brazil, particularly as a complication of sickle cell anemia ${ }^{(1)}$ and schistosomiasis, ${ }^{(2)}$ and discussing the role of imaging methods in the evaluation of this disease. ${ }^{(3-5)}$ We would like to report another uncommon cause of $\mathrm{PH}$, pulmonary capillary hemangiomatosis ( $\mathrm{PCH})$, and describe the important role of imaging methods in establishing the diagnostic suspicion of this condition.

A 25-year-old male nonsmoker presented to the pulmonology department with a threemonth history of rapidly progressive dyspnea. Physical examination revealed digital clubbing, and he was tachypneic and cyanotic, requiring supplementary oxygen. Heart auscultation and chest examination were unremarkable, and examination of the abdomen revealed a slightly enlarged liver. A transesophageal echocardiogram showed enlargement of the main pulmonary artery and right heart chamber. Arterial blood gas analysis showed the following results: $\mathrm{pH}$, 7.46; $\mathrm{PaCO}_{2}, 26.6 \mathrm{mmHg}$; and $\mathrm{PaO}_{2}, 51.8 \mathrm{mmHg}$. A chest $X$-ray showed dilatation of the main and central pulmonary arteries with a nonspecific interstitial infiltrate. Chest CT angiography allowed us to exclude pulmonary embolism and revealed diffuse centrilobular ground-glass opacities (GGOs) and marked dilatation $(36 \mathrm{~mm})$ of the main pulmonary artery (Figure 1). The GGOs were bilateral and symmetrical, with no thickening of the interlobular septa. On a pulmonary function test, DLCO was 20\%. Anticoagulation therapy with heparin was started and initially improved the symptoms slightly. Pulmonary catheterization demonstrated a mean pulmonary artery pressure of $65 \mathrm{mmHg}$ and a negative vasoactive intestinal peptide result. The pulmonary artery occlusion pressure was $13 \mathrm{mmHg}$, and cardiac output was
$2.9 \mathrm{~L} / \mathrm{min}$. Because of the diagnostic suspicion of $\mathrm{PCH}$, the patient was placed on the waiting list for lung transplantation. Despite the treatment with heparin and furosemide, the condition of the patient gradually deteriorated, and he died two months after admission. An autopsy revealed prominent dilation of the right heart chambers and of the pulmonary artery, as well as diffuse alveolar hemorrhage. Microscopic examination of the lungs showed well-demarcated areas with dense proliferation of capillary channels within alveolar walls and surrounding walls of pulmonary venules and veins, which supported the diagnosis of PCH (Figure 2).

The $\mathrm{PH}$ syndrome is a heterogeneous group of conditions with the common feature of pulmonary artery involvement, resulting in increased pulmonary vascular resistance, hypertrophy, and right ventricular dilatation that can lead to significant cardiac dysfunction (cor pulmonale) and death. Currently, $\mathrm{PH}$ is defined as a resting mean pulmonary artery pressure $\geq 25 \mathrm{mmHg}$, as measured by right heart catheterization. ${ }^{(5,6)}$

$\mathrm{PCH}$ is an extremely rare cause of primary $\mathrm{PH}$ and occurs most commonly in adults aged 20-40 years, but it has been reported to occur in all age groups and shows no sex predilection. The clinical presentation of $\mathrm{PCH}$ is very nonspecific and most frequently includes dyspnea and fatigue. Other complaints are chest pain, chronic cough, peripheral edema, cyanosis, and syncope. ${ }^{(3)}$ Hemoptysis can be a very useful sign in order to differentiate PCH from pulmonary veno-occlusive disease (PVOD), because it is not found in PVOD.

On chest X-rays, PCH appears as diffuse or bibasilar reticulonodular opacities. Signs of pulmonary arterial hypertension (PAH), such as enlarged central pulmonary arteries and dilatation on the right side of the heart, can also be present. CT scans can show diffuse, ill-defined, centrilobular GGOs and signs consistent with $\mathrm{PAH}$ 

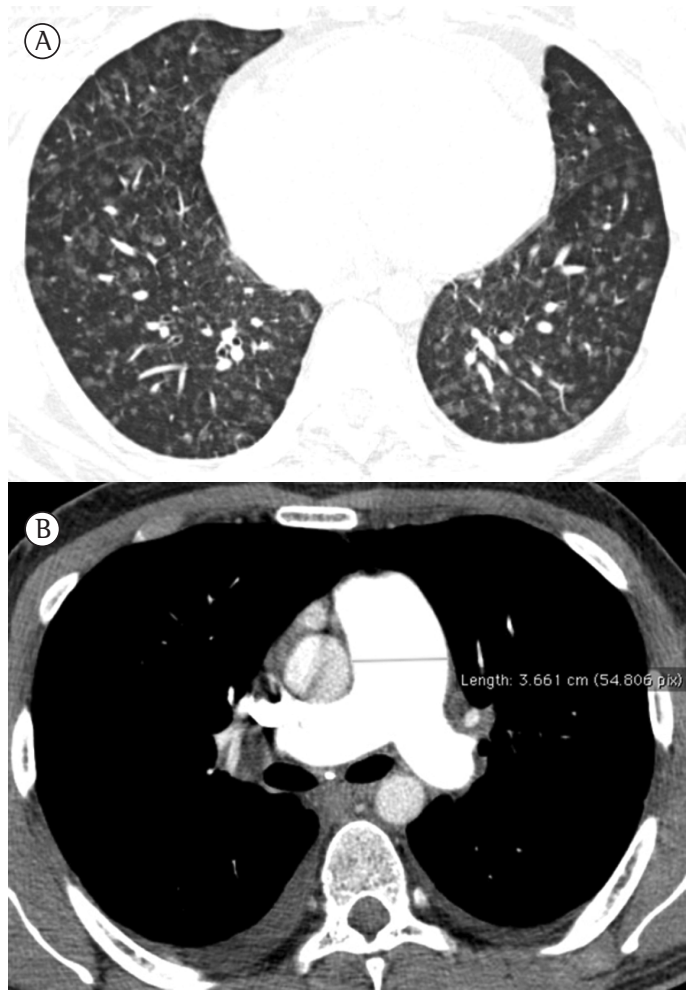

Figure 1 - $\ln$ A, HRCT scan showing diffuse centrilobular ground-glass opacities. In B, chest CT angiography image demonstrating marked dilatation of the main pulmonary artery (diameter, $36 \mathrm{~mm}$ ) and bilateral pleural effusion.

(main pulmonary artery diameter $>3 \mathrm{~cm}$ )..$^{(4,5)}$ The association of centrilobular GGOs with the findings mentioned above is an important clue for differentiating $\mathrm{PCH}$ from classic causes of this GGO pattern, such as viral infections and acute hypersensitivity pneumonitis. $\mathrm{PCH}$ and PVOD should be suspected in patients with PAH associated with hemoptysis or hemorrhagic pleural effusion and interstitial lung infiltrates.

The final diagnosis of $\mathrm{PCH}$ is made by lung biopsy. Open lung biopsy is the most accurate method, but various patients do not have the necessary clinical conditions to undergo such a procedure. Transbronchial biopsy has been considered a highly risky procedure due to the possibility of bleeding. The proliferation of capillary channels within alveolar walls is the main histological characteristic of $\mathrm{PCH} .{ }^{(6)}$ No specific treatment other than lung transplantation is available.

In conclusion, $\mathrm{PCH}$ is an extremely rare cause of primary $\mathrm{PH}$ and has a poor prognosis. This condition must be considered when a patient

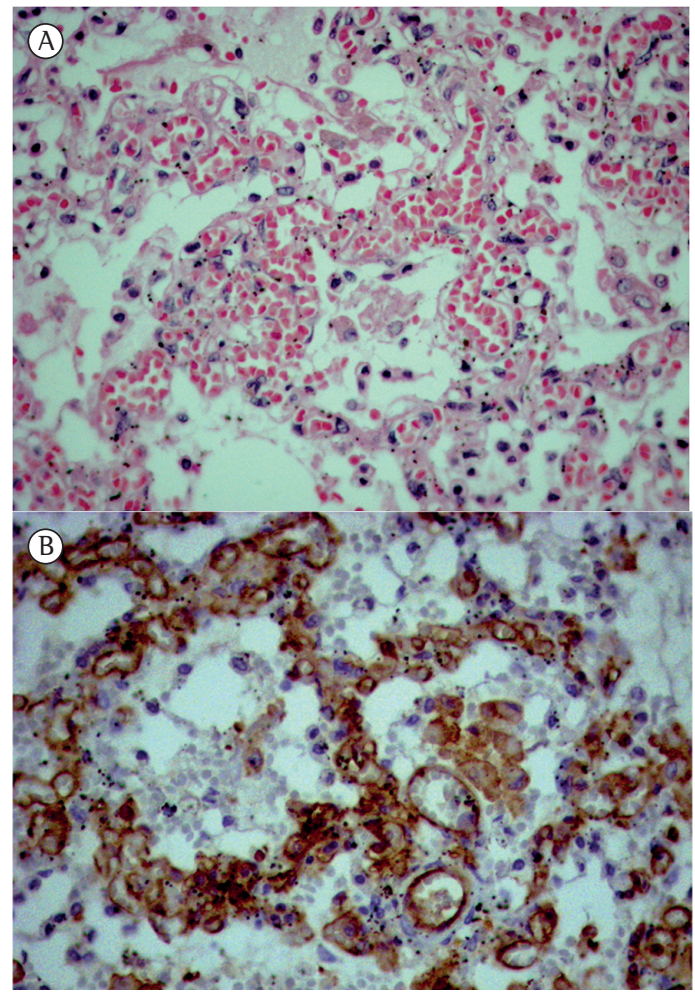

Figure 2 - $\ln$ A, photomicrograph showing alveolar septal thickening with intense capillary proliferation (HEtE; original magnification, $\times 400$ ). In $\mathrm{B}$, photomicrograph showing capillaries of the alveolar walls with marked CD31 positivity (immunohistochemistry; magnification, ×400).

with PAH presents hemoptysis or hemorrhagic pleural effusion and interstitial lung infiltrates, especially in the presence of centrilobular GGOs and sparse, smoothly thickened interlobular septa. Currently, biopsy is the only method to confirm the diagnosis of $\mathrm{PCH}$.

\section{lgor Murad Faria}

Resident, Department of Radiology, Federal University of Rio de Janeiro, Rio de Janeiro, Brazil

\section{Leonardo Hoehl Carneiro}

Physician, Department of Anatomic Pathology, Federal University of Rio de Janeiro, Rio de Janeiro, Brazil

\section{Teófilo Augusto Araújo Tiradentes} Resident, Department of Anatomic Pathology, Federal University of Rio de Janeiro, Rio de Janeiro, Brazil 


\section{Gláucia Zanetti \\ Professor of Clinical Medicine, Petrópolis School of Medicine, Petrópolis, Brazil}

\section{Edson Marchiori \\ Associate Professor of Radiology, Federal University of Rio de Janeiro, Rio de Janeiro, Brazil}

\section{References}

1. Padua Al, Martinez JA. Sickle cell anemia: a significant potential cause of pulmonary hypertension in Brazil. J Bras Pneumol. 2012;38(1):143-4. http://dx.doi.org/10.1590/ S1806-37132012000100021 PMid:22407053

2. Correa Rde A, Moreira MV, Saraiva JM, Mancuzo EV, Silva LC, Lambertucci JR. Treatment of schistosomiasis- associated pulmonary hypertension. J Bras Pneumol. 2011;37(2):272-6. PMid:21537664

3. Hochhegger B, Marchiori E, Irion K, Souza AS Jr, Volkart J, Rubin AS. Magnetic resonance of the lung: a step forward in the study of lung disease. J Bras Pneumol. 2012;38(1):105-15. http://dx.doi.org/10.1590/S180637132012000100015 PMid:22407047

4. Vonk Noordegraaf A. The image of pulmonary hypertension. J Bras Pneumol. 2011;37(3):283-4. PMid:21755196

5. Hovnanian A, Menezes E, Hoette S, Jardim C, Jasinowodolinski D, Souza R. The role of imaging techniques in the assessment of pulmonary circulation. J Bras Pneumol. 2011;37(3):389-403. http://dx.doi. org/10.1590/S1806-37132011000300017 PMid:21755197

6. 6Almagro P, Julià J, Sanjaume M, González G, Casalots J, Heredia JL, et al. Pulmonary capillary hemangiomatosis associated with primary pulmonary hypertension: report of 2 new cases and review of 35 cases from the literature. Medicine (Baltimore). 2002;81(6):417-24. http://dx.doi. org/10.1097/00005792-200211000-00002 